IZA DP No. 4862

Enhanced Fee-for-Service Model and Access to Physician Services: Evidence from Family Health Groups in Ontario

Jasmin Kantarevic

Boris Kralj

Darrel Weinkauf

April 2010 


\title{
Enhanced Fee-for-Service Model and Access to Physician Services: Evidence from Family Health Groups in Ontario
}

\author{
Jasmin Kantarevic \\ Ontario Medical Association \\ and IZA \\ Boris Kralj \\ Ontario Medical Association \\ Darrel Weinkauf \\ Ontario Medical Association
}

Discussion Paper No. 4862

April 2010

IZA

P.O. Box 7240

53072 Bonn

Germany

Phone: +49-228-3894-0

Fax: +49-228-3894-180

E-mail: iza@iza.org

Any opinions expressed here are those of the author(s) and not those of IZA. Research published in this series may include views on policy, but the institute itself takes no institutional policy positions.

The Institute for the Study of Labor (IZA) in Bonn is a local and virtual international research center and a place of communication between science, politics and business. IZA is an independent nonprofit organization supported by Deutsche Post Foundation. The center is associated with the University of Bonn and offers a stimulating research environment through its international network, workshops and conferences, data service, project support, research visits and doctoral program. IZA engages in (i) original and internationally competitive research in all fields of labor economics, (ii) development of policy concepts, and (iii) dissemination of research results and concepts to the interested public.

IZA Discussion Papers often represent preliminary work and are circulated to encourage discussion. Citation of such a paper should account for its provisional character. A revised version may be available directly from the author. 
IZA Discussion Paper No. 4862

April 2010

\section{ABSTRACT}

\section{Enhanced Fee-for-Service Model and Access to Physician Services: Evidence from Family Health Groups in Ontario}

We study an enhanced fee-for-service model for primary care physicians in the Family Health Groups (FHG) in Ontario, Canada. In contrast to the traditional fee-for-service (FFS) model, the FHG model includes targeted fee increases, extended hours, performance-based initiatives, and patient enrolment. Using a long panel of claims data, we find that the FHG model significantly increases physician productivity relative to the FFS model, as measured by the number of services, patient visits, and distinct patients seen. We also find that the FHG physicians have lower referral rates and treat slightly more complex patients than the comparable FFS physicians. These results suggest that the FHG model offers a promising alternative to the FFS model for improving access to physician services.

JEL Classification: I10, I12, I18

Keywords: access to physician services, physician productivity, remuneration, primary care, Family Health Groups, Ontario, Canada

Corresponding author:

Jasmin Kantarevic

Ontario Medical Association

525 University Avenue

Toronto, ON M5G 2K7

Canada

E-mail: jasmin_kantarevic@oma.org 


\section{Introduction}

Many recent primary health care reforms aim to address perceived shortcomings of the traditional fee-for-service (FFS) model. For example, the Patient-Centered Medical Homes $(\mathrm{PCMH})$ in the United States focus on coordinated and integrated care, quality and safety, enhanced access, and payment system that rewards value. Similar principles are also incorporated in the recent Quality and Outcomes Framework (QOF) in the United Kingdom and the Patient Enrolment Models (PEM) in Ontario, Canada ${ }^{1}$.

The promise of these reforms is to improve access and quality and reduce cost of delivering primary health care. However, it is still not well understood how the new models of care compare to the traditional FFS model. Some models, such as the PCMH in the U.S., are still in the pilot project stage and only preliminary results are currently available $^{2}$. Limited evidence from the more mature models, such as the British QOF and the Ontario PEM, suggests that it matters how physicians are paid ${ }^{3}$. However, this evidence is sometimes based on small samples which may not be representative of the larger physician population. Furthermore, few studies rely on a formal economic model to interpret their empirical results, which sometimes makes it difficult to recognize a common incentive structure in different institutional settings. Most importantly, almost all studies are based on non-randomized, observational data ${ }^{4}$. This renders the inference based on the cross-sectional or before-after comparisons problematic. For this reason,

\footnotetext{
${ }^{1}$ For a brief overview of these reforms, see the report by Robert Graham Center (2007) for the PCMH, Smith and York (2004) for the QOF, and Russell et al. (2009) and Rosser et al. (2010) for the PEMs.

${ }^{2}$ See for example Rosenthal (2010).

${ }^{3}$ For studies of the impact of financial incentives on quality indicators in the QOF, see for example Campbell et al. (2007), Hippisley-Cox et al. (2007), Steel et al. (2007), Tahrani et al. (2007), McGovern et al. (2008), and Sutton et al. (2010). For evidence on the PEMs, see Glazier et al. (2009) and Russell et al. (2009). See also and Devlin and Sarma (2008) for a more general study of the impact of remuneration schemes on Canadian family physicians.

${ }^{4}$ For example, the QOF was introduced universally and simultaneously across the UK without any piloting.
} 
many recent studies are perhaps best interpreted as correlation studies that need further validation using suitable control groups.

In this paper, we contribute to this emerging literature in several ways. First, we study an enhanced fee-for-service model known as the Family Health Group (FHG) that was introduced in Ontario in 2003. This model shares elements common to both the U.S. and the U.K. reforms, such as patient-centered care (through enrolment), enhanced access to physicians, and performance-based initiatives. Second, we develop a stylized economic model of physician behaviour in the FHG model. This model is useful as a framework for understanding how physicians respond to the FHG incentives and as a guide for our empirical analysis. The model can also serve as a starting point to study incentive structures in other reforms. Third, we use a methodology that can be fruitfully exploited to evaluate primary care reforms when only observational data is available. Specifically, we use the propensity score matching to select control groups of FFS physicians and we use the difference-in-difference model with fixed physician effects and linear trends to evaluate the FHG impact. We also explore multiple 'experiments' and dynamics of the FHG impact to further validate the causal interpretation of changes in physician behaviour. Lastly, we use a sample significantly larger than in most previous studies. This sample includes almost all primary care physicians in Ontario and it spans a period of eleven years before and five years after the FHG model was introduced.

We find that joining the FHG model has a meaningful impact on physician productivity relative to the traditional FFS model, as measured by the number of clinical services, visits, and distinct patients seen. The estimated productivity gain is about six to ten percent, equivalent to about two to three additional weeks of work per year. 
Furthermore, the impact occurs within the first year of joining the FHG model and persists over time. The impact is also stable across physician groups defined by age, sex, and location of practice. We also find that FHG physicians have significantly lower referral rates to specialists and treat slightly more complex patients than the comparable FFS physicians. Based on these results, the FHG model seems to be a promising alternative to the traditional FFS model for improving access to physician services.

The paper is organized as follows. The next section provides a brief introduction to the patient enrolment models in Ontario, including a detailed comparison between the traditional FFS model and the FHG model. Section 3 presents a theoretical analysis of the decision of FFS physicians to join the FHG model and the impact of this decision on their practice profile. Section 4 describes our data and empirical strategy. Section 5 discusses the results and Section 6 concludes.

\section{Institutional Background}

Primary care physicians in Ontario participate in a wide spectrum of patient enrolment models (PEM). These models were introduced in a recent primary care reform that aimed to provide alternatives to the traditional FFS model. The reform dramatically changed how primary care is provided in Ontario. Between 2002 and 2008, the percent of primary care physicians participating in the PEMs increased from less than 5 percent (400 physicians) to over 70 percent ( 8,000 physicians).

The PEMs are of two main types. The harmonized models, such as the Family Health Network (FHN) and the Family Health Organization (FHO), are blended capitation models. The non-harmonized models, such as the Family Health Groups 
(FHG) and the Comprehensive Care Model (CCM), are enhanced fee-for-service models. Physicians are free to choose which PEM to join, but they can also remain in the traditional FFS model. As shown in Table 1, about two thirds of physicians currently participate in the PEMs, while the rest of physicians practice in the FFS model.

The PEMs share four main elements. First, all PEMs are group models, with the exception of the solo CCM model. In most models, the minimum size of the group is three physicians. Second, the PEMs are based on a formal enrolment of patients. The patient enrolment is a required contractual obligation in the harmonized models, but it is strongly encouraged through the enrolment-based fees and payments in all models ${ }^{5}$. Third, most physicians in the PEMs are eligible for performance-based initiatives such as preventive care bonuses and chronic disease incentives. Lastly, the PEM contract stipulates that the physician group provides scheduled extended hours. For example, the minimum requirement for the group of three physicians is to provide a three-hour block of care per week per physician during the after-hour period (evenings on weekdays or any time on weekends and holidays).

While the PEMs share common elements, there are also subtle differences between various models. These differences are often important from the policy perspective. For example, it is important to know how cost-effective each PEM is relative to the traditional FFS model. In addition, studying a specific PEM can help in understanding how physicians respond to well-defined organizational and compensation elements. Therefore, the policy makers are often interested not in the performance of the

\footnotetext{
5 Even though enrolment is optional in the non-harmonized models, almost all financial incentives incremental to the traditional FFS model are based on patient enrolment.
} 
entire group of PEMs relative to the FFS model, but in the performance of each PEM individually.

In this paper, we focus on the performance of physicians in the FHG model relative to the traditional FFS model. The FHG model was introduced in 2003 and quickly became the most popular single compensation model for the primary care physicians in Ontario, especially among full-time physicians. In addition, the FHG model is often the first transit point for physicians who migrate from the FFS environment to the PEMs. For example, about 1,500 physicians who joined the capitation models between 2007 and 2008 were previously in the FHG model.

To clarify the comparison between the FFS and FHG models, we present their main organizational and compensation elements in Table 2. As mentioned earlier, the FHG model is a group model based on the patient enrolment and extended hours. None of these elements formally exist in the FFS model. On the other hand, the FHG physicians receive the full fee-for-service value for services they provide, just like the FFS physicians. However, the FHG model also provides financial incentives that are entirely absent from the FFS model. These incentives include targeted fee increases for comprehensive care services provided during regular hours (10 percent premium) and during after-hours $(20 \text { percent premium })^{6}$. To encourage patient enrolment, these premiums are paid only for services provided to enrolled patients. In addition, the FHG physicians are also paid a small Comprehensive Care Capitation (CCC) fee for each

\footnotetext{
${ }^{6}$ Nineteen services are eligible for the 10 percent premium during regular hours, which include assessments in office, emergency department and patient home; pap smear, immunization, flu shot, and annual health exam; primary mental health, HIV, and palliative care; and diabetic assessment. Ten services are eligible for the 20 percent premium during after-hours, which include assessments in office, emergency department and patient home; pap smear, immunization, flu shot, and annual health exam; primary mental health, HIV, and palliative care. Eight out of ten services eligible for the premium during after-hours are contained in the list of nineteen services eligible for the premium during regular hours.
} 
enrolled patient ${ }^{7}$. This fee, which is adjusted for the patient age and sex, is paid for commitment to provide comprehensive care services to enrolled patients, and not for the actual provision of services ${ }^{8}$. For this reason, the CCC fee is perhaps best interpreted as a transfer designed to meet the participation constraint of FFS physicians interested in joining the FHG model and, more generally, to address historical pay inequity between specialists and family physicians. Lastly, the FHG physicians are also eligible for performance-based initiatives. These include preventive care bonuses (pap smears, mammograms, childhood immunizations, flu shots, colorectal screening), special payments (obstetrical deliveries, hospital services, palliative care, prenatal care, home visits), chronic disease management fees (diabetes, congestive heart failure), and incentives to enroll patients who have no regular family doctor ${ }^{9}$. Most of these initiatives reward physicians if they reach specific service targets or provide specific type of services. In this respect, these initiatives resemble standard fee premiums.

\section{Economic Model of Family Health Groups}

To analyze how differences between the FFS and FHG models affect physician behaviour, we utilize a stylized labour supply model that distinguishes between regular

\footnotetext{
${ }^{7}$ The average annual value of this fee is $\mathrm{C} \$ 25.8$. For comparison, the fee value for a single intermediate assessment that constitutes the bulk of physician billings is $\mathrm{C} \$ 32.35$.

${ }^{8}$ The CCC fee is adjusted by the age-sex specific modifier which includes 19 five-year age categories for each sex. The modifier ranges from 0.44 for males 10-14 years of age to 2.71 for females over 90 years of age, with the provincial average standardized to 1 .

${ }^{9}$ Preventive care bonuses have targets based on the ratio of patients receiving the service to the number of patients eligible for the service, similar to how the QOF indicators in the UK are defined. Special payments are based on achieving specific minimum service targets (e.g. the bonus is $\mathrm{C} \$ 5,000$ if selected hospital services are at least $\mathrm{C} \$ 2,000$ per annum). Chronic disease management fees are paid annually for providing required elements of service. The incentive to attach patients with no family doctor are paid as a one-time payment at the time of attachment, and differentiate between regular patients, patients discharged from hospital, complex/vulnerable patients, and mothers with newborns.
} 
hours of work and after hours. We then use this model to analyze the decision of FFS physicians to join the FHG model and the impact of this decision on their practice profile.

\section{A. Fee-for-Service Environment}

The physician problem in the FFS environment can be stated as follows:

(1) $p_{1} x_{1}+p_{2} x_{2}+m=c$

(2) $T=l+t_{1} x_{1}+t_{2} x_{2}$

(3) $U=u\left(c, l, x_{2}\right)$

(4) $x_{1}>0, x_{2} \geq x_{\min }=0$

Equation (1) specifies the budget constraint. We assume that the physician receives income from three main sources: services provided during regular hours $\left(p_{1} x_{1}\right)$, services provided during after hours $\left(p_{2} x_{2}\right)$, and non-labour income $(m)$, where $p_{i}$ and $x_{i}$ can be interpreted as the average fee and count of services provided during period $i$, with $i=1$ for regular hours and $i=2$ for after hours. We also assume that the physician spends her entire income on the composite consumption good $c$. Equation (2) describes the time constraint. The physician has $T$ units of time which she can allocate to either leisure $l$ or to provision of medical services during regular hours $\left(t_{1} x_{1}\right)$ or during after hours $\left(t_{2} x_{2}\right)$, where $t_{i}$ represents the units of time required to provide one unit of service $x_{i}$. Equation (3) describes physician preferences. We assume that marginal utilities of consumption and leisure are positive $\left(u_{C}, u_{l}>0\right)$ but non-increasing $\left(u_{C C}, u_{l l} \leq 0\right)^{10}$. To allow for preferences for the timing of work, we include $x_{2}$ as a separate argument in the utility

\footnotetext{
${ }^{10}$ In the literature, the case with $u_{\mathrm{CC}} \rightarrow 0$ is known as the profit maximization hypothesis, while the case with $u_{\mathrm{CC}} \rightarrow-\infty$ as the income target hypothesis. See for example McGuire and Pauly (1991) and McGuire (2000).
} 
function and assume that $u_{2}<0$ and $u_{22} \leq 0^{11}$. For convenience, we also assume that the utility function is separable. Lastly, the two constraints in (4) require that the physician provides some services during regular hours but may choose whether to provide any after-hour services. In the second inequality, $x_{\min }$ represents the minimum after-hours requirement, which is equal to zero in the FFS environment.

This stylized model therefore captures three potential differences between work during regular hours and after hours: prices $\left(p_{\mathrm{i}}\right)$, technology $\left(t_{\mathrm{i}}\right)$, and preferences.

The first-order conditions for this problem are:

(5) $u_{c} p_{1}-u_{l} t_{1}=0$

(6) $u_{c} p_{2}-u_{l} t_{2}+u_{2}+\lambda=0$

(7) $\lambda\left(x_{2}-x_{\min }\right)=0$

where $\lambda \geq 0$ is the Lagrangean multiplier associated with the after-hours constraint and equation (7) holds with complementary slackness. These conditions can be simplified into:

(8) $\frac{p_{1}}{t_{1}}=\frac{u_{l}}{u_{c}} \geq \frac{p_{2}}{t_{2}}+\frac{u_{2}}{t_{2} u_{c}}$

The first term $\left(p_{1} / t_{1}\right)$ represents the marginal return per unit of time to work during regular hours. Similarly, $u_{l} / u_{c}$ and $p_{2} / t_{2}+u_{2} / t_{2} u_{c}$ represent the marginal returns per unit of time to leisure and work during after-hours, respectively. Therefore, the physician allocates her time between the three activities by comparing their marginal monetary returns per unit of time. At the interior solution $(\lambda=0)$, these returns are equalized and the physician is indifferent between allocating an additional unit of time to

${ }^{11}$ With $u_{2}=0$, the physician will completely specialize in one type of service, depending on the relation between $p_{1} / t_{1}$ and $p_{2} / t_{2}$. 
work during regular hours, leisure, and work during after-hours. At the corner solution ( $\lambda>0$ ), the physician is indifferent between work during regular hours and leisure, but she provides no after-hour services.

\section{B. Family Health Group Environment}

The physician problem in the FHG environment differs in three main ways ${ }^{12}$. First, the physician is now required to provide a minimum number of after-hour services, which modifies the after-hour constraint by $\Delta x_{\min }>0$. Second, the physician receives a comprehensive care premium of $k_{1}$ for selected services provided to enrolled patients during regular hours and an after-hours premium of $k_{2}$ for selected services provided to enrolled patients provided during after hours. If we let $a$ represent the fraction of services eligible for the premiums and $b$ the fraction of patients who are enrolled, the fee increases can be written as $\Delta p_{1}=a b k_{1} p_{1}>0$ and $\Delta p_{2}=a b k_{2} p_{2}>0$. Lastly, the physician also receives a Comprehensive Care Capitation fee for each enrolled patient. We interpret this fee as an increase in the non-labour income by $\Delta m>0$, where $\Delta m$ is the product of the per-patient capitation fee and the number of patients to whom the physician is the primary care provider ${ }^{13}$.

\footnotetext{
${ }^{12}$ We abstract from differences in the group size between the FFS and FHG models. The FHG physician groups are loosely defined and the contract does not require that physicians share the same physical office. In addition, all payments are made to individual physicians, with the exception of Telephone Health Advisory, which represents a very minor source of income for the FHG physicians. In addition, we abstract from performance-based initiatives for analytical convenience and because these incentives reward physicians if they reach specific service targets, or provide selected services. These initiatives can then be considered as fee premiums, which would be incorporated in our model with an appropriate reinterpretation of $p_{1}$ and $p_{2}$.

${ }^{13}$ Note that the physician implicitly chooses the number of patients by her choice of how many services to provide. Once the number of patients is determined, the CCC fee is correctly interpreted as a non-labour income because this fee is paid in lieu of commitment to provide comprehensive care services, not for the actual provision of services, and this commitment does not require additional physician time.
} 


\section{Decision to Join Family Health Group}

Let $\left(x_{1}^{0}, x_{2}^{0}\right)$ denote the optimal solution to the physician problem in the FFS environment and let $v$ be the associated value function. Using the envelope theorem, the change in $v$ from joining the FHG model can be approximated by:

(9) $\Delta v=u_{c} x_{1}^{0} \Delta p_{1}+u_{c} x_{2}^{0} \Delta p_{2}+u_{c} \Delta m-\lambda \Delta x_{\min }$

Rearranging the terms, the decision to join the FHG model can be written as:

$$
x_{1}^{0} \Delta p_{1}+x_{2}^{0} \Delta p_{2}+\Delta m \geq\left(\lambda / u_{c}\right) \Delta x_{\min }
$$

The left side of equation (10) represents the expected gain in income evaluated at the service profile prior to joining the FHG model. This expected gain is similar to what the Ministry of Health and Long-Term Care provides in its free revenue reports to FFS physicians interested in joining the FHG model. In our empirical analysis, we construct a similar measure of the expected income gain, using the actual service and patient profiles prior to joining the FHG model.

The right side of equation (10) can be interpreted as the monetary value of disutility from increasing the after-hours requirement in the FHG model relative to the FFS environment. When the after-hour constraint is not binding $(\lambda=0)$, the decision rule in (10) implies that the FFS physician would always join the FHG model. When the after-hours constraint is binding $(\lambda>0)$, the first order conditions (5) and (6) can be used to write the right side of (10) as:

(11) $\frac{\lambda}{u_{c}} \Delta x_{\min }=\left(\frac{t_{2}}{t_{1}} p_{1}-p_{2}-\frac{u_{2}(0)}{u_{c}\left(p_{1} x_{1}^{0}+m\right)}\right) \Delta x_{\min }$

This expression implies that the physician is less likely to join the FHG model the more productive she is during regular hours relative to after-hours, the higher is the 
average fee for services during regular hours, the lower is the average fee for services during after hours, the higher is the physician non-labour income, and the higher is the physician disutility associated with working during after hours. The physician is also less likely to join the FHG model the higher is the after-hours constraint relative to their current practice. In our empirical analysis, we proxy for these factors by using age, gender, location, the expected income gain, and the number of working weekends and holidays to predict physician decision to join the FHG model.

\section{Impact of Joining Family Health Group on Practice Profile}

The FHG impact on the physician practice profile depends on the relative strength of income and substitution effects arising from changes in fees and non-labour income. When income effects are negligible and the physician is at least as productive during after-hours as during regular hours $\left(t_{2} \leq t_{1}\right)$, the number of total services $\left(x_{1}+x_{2}\right)$ will unambiguously increase ${ }^{14}$. These two conditions are sufficient, but not necessary, for both cases when the after-hour constraint is binding and when it is not.

To assess whether the condition $t_{2} \leq t_{1}$ is likely to hold, we estimated the average time per service during regular hours and after-hours. For this purpose, we used the sample of FHG physicians in the fiscal 2008/09 and separated the services claimed with the after-hour premium code from other services. The average time per service was then calculated as the weighted average of time per service for the top 50 services in each time period, where the weights used were the proportion of all services that each service

\footnotetext{
${ }^{14}$ See Appendix.
} 
represents ${ }^{15}$. Our estimates indicate that the average time per service is about 9.2 minutes for services performed during regular hours and about 11 minutes for services performed during after-hours. This finding suggests that physicians spend on average more time per service during after-hours than regular hours (i.e. $t_{2}>t_{1}$ ). Therefore, the first of two sufficient conditions for the increase in the total number of services is unlikely to hold. In addition, the empirical evidence on the second sufficient condition - the strength of income effects - is quite mixed ${ }^{16}$. Therefore, the impact of joining the FHG model ultimately remains an empirical question.

\section{Data and Empirical Framework}

\section{A. Data}

The data comes from the Ontario Health Insurance Plan (OHIP) fee-for-service claims for the fiscal years 1992 through 2008. This period includes eleven years before and five years after the FHG model was introduced in 2003.

The OHIP data has several advantages for our analysis. It includes virtually all family physicians in Ontario who are potentially affected by the introduction of the FHG model $^{17}$. In addition, the seventeen-year panel improves our chances to distinguish significant deviations in physician behaviour from long-term secular trends. The data is also reported for each physician-patient encounter and for each type of service provided

\footnotetext{
${ }^{15}$ The time estimates for each fee code come from the report prepared by the Resource-Based Relative Value Schedule (RBRVS) Commission of Ontario in 2002 based on a methodology similar to that for the Medicare Relative Value Schedule in the United States. The RBRVS report does not have estimates for all services on our list: the percentage of matched services is $82 \%$ for the after-hour services and $72 \%$ for the regular hours.

${ }^{16}$ See for example Kantarevic et al. (2008), Rizzo (1994), Tai-Seale Ming et al. (1998), and Yip (1998).

${ }^{17}$ Physicians with no fee-for-service claims are not included in the OHIP data. This group includes mainly salaried physicians who represent less than 1 percent of all family physicians.
} 
during this encounter. Such detailed data enables us to examine a rich set of outcomes, including the number and type of clinical services, the number of total patient visits and distinct patients seen, and the number of referrals to specialists. Lastly, the claims data alleviates problems such as measurement error and recall bias that are sometimes present in self-reported surveys. On the other hand, the main disadvantage of the OHIP data is that it contains limited demographic information for patients and physicians (age, sex, and location only).

Our full sample includes 10,111 family physicians with some fee-for-service claims in 2002, the immediate year before the FHG model was introduced ${ }^{18}$. Therefore, our sample excludes physicians who ceased to practice prior to 2002 and those who started to practice after 2002. The full sample is divided between 5,260 physicians who joined the FHG model in any year between 2003 and 2008 (the treatment group) and 4,851 physicians who never joined the FHG model (the comparison group).

The summary statistics for this sample, as of 2002, are presented in the first two columns in Table 3. These statistics show some striking differences in pre-treatment covariates between the treatment and comparison physicians. Specifically, the treatment sample is on average 4 years younger and has about 5 percent fewer male physicians and about 6 percent fewer physicians residing in the Toronto Central region relative to the comparison sample. More dramatically, the expected gain from joining the FHG model is twice as high for the treatment physicians compared to the comparison physicians. The treatment physicians also work about 50 percent more weekends and holidays than the comparison physicians. All of these differences are statistically significant. Moreover, the differences in the pre-treatment outcomes are also statistically significant, indicating

\footnotetext{
${ }^{18}$ The sample excludes 379 physicians who were in harmonized models in 2002.
} 
that the treatment physicians provide substantially more annual services and visits and see more distinct patients than the comparison physicians.

These results indicate that physicians who joined the FHG model were positively selected from the population of all family physicians. To partially address this selection problem, we use the propensity score matching to select a sub-sample of comparison physicians with observed covariates most similar to the treatment physicians ${ }^{19}$. Specifically, we first estimate the probability of joining the FHG model (the propensity score) based on physician age, gender, location, expected gain from joining the FHG model, and the number of working weekends and holidays using the full sample of family physicians in 2002. Our specification of the probability model is based on the algorithm by Dehejia and Wahba (2002) which starts with a linear specification and then adds higher-order terms, if required, until the treatment and comparison samples are balanced on each covariate. Based on this algorithm, our probability model includes quartic functions of age, expected gain, and working weekends and holidays; an indicator for male physicians; an interaction term between the male indicator and age; and 14 regional indicators $^{20}$.

In the second step, we use the nearest neighbor matching to select which comparison physicians to include in the final sample. In the nearest neighbor matching, each treatment physician is matched on the propensity score to the nearest comparison physician. We also use the replacement option with the nearest neighbor matching which allows a comparison physician to be matched to more than one treatment physician. This

\footnotetext{
${ }^{19}$ For theoretical reviews, see for example Rosenbaum and Rubin $(1983,1985)$ and Dehejia and Wahba (2002). For implementation in STATA, see Leuven and Sianesi (2003).

${ }^{20}$ The role of propensity score is to solve the dimensionality problem associated with the exact matching on multiple covariates and as such has no behavioural assumptions attached to it.
} 
option is preferred to matching without replacement if the distribution of propensity scores is very different between the comparison and treatment groups ${ }^{21}$. In our sample, the replacement option seems more appropriate given the empirical distribution of propensity scores shown in Figure 1.

The summary statistics for the matched comparison group are shown in the third column of Table 3. This sample consists of 1,734 physicians compared to 4,851 physicians in the full comparison sample. The matched comparison physicians are quite similar to the treatment physicians with respect to the pre-treatment covariates and outcomes. Moreover, none of the differences observed in the full sample are statistically significant. Therefore, the propensity score matching seems to significantly reduce the pre-treatment imbalances between treatment and comparison physicians in our sample.

\section{B. Empirical Framework}

Our empirical strategy relies on contrasting changes in outcomes for the treatment and comparison physicians before and after the FHG model was introduced. This strategy critically depends on comparability of physicians in the two groups. While the propensity score matching ensures that the treatment and matched comparison physicians are similar at one point in time (just prior to the introduction of the FHG model), the two groups also need to have comparable trends in outcomes over time.

To examine the common trend assumption, we calculated the weighted average for three main outcomes (log of annual services, visits, and distinct patients) for each group over the sample period. The results are presented in Figures 2 to 4 . The figures show that the outcome trends for the two groups were quite similar until 2002, but then

\footnotetext{
${ }^{21}$ See for example Dehejia and Wahba (2002).
} 
significantly diverged. In addition, as shown by the small bars in the figures, the most significant changes occurred between 2003 and 2005, when over thousand physicians joined the FHG model in each year. These figures suggest that the treatment physicians permanently shifted their productivity profiles upward after 2002. Moreover, the figures imply that this shift occurred soon after the physicians joined the FHG model.

While these changes coincide with the introduction of the FHG model, this relationship of course may not be causal. The main concern is that physicians choose whether to join the FHG model, and factors that determine this choice may also be correlated with their productivity. To address this concern, we use the correlated random trend model (Wooldridge, 2005). This model resembles the standard difference-indifferences model, except that we calculate the differences for the same physicians over time rather than the same groups. Importantly, the model also controls for physicianspecific linear trends in outcomes.

Specifically, our baseline model is:

$$
y_{i t}=\gamma_{i}+\lambda_{t}+\theta_{i} t+w_{i t}^{\prime} \beta+\delta F H G_{i t}+u_{i t}
$$

where $y_{i t}$ represents the outcome of interest for physician $i$ in year $t ; \gamma_{i}$ is the set of physician fixed effects; $\lambda_{t}$ is the set of year fixed effects; $\theta_{i}$ is the trend for physician $i$; $w_{i t}$ is the set of time-varying physician characteristics; and $F H G_{i t}$ is the treatment indicator equal to 1 if the physician is in the FHG model at time $t$ and 0 if the physician is in the FFS model.

In this model, $\gamma_{i}$ controls for mean differences in outcomes across physicians, $\lambda_{t}$ controls for trends in outcomes common to all physicians, and $\theta_{i}$ captures the physicianspecific linear trend in outcomes. Therefore, the coefficient $\delta$ represents the difference in 
outcomes for treatment and comparison physicians, controlling for fixed physician and year effects and physician-specific linear trends. This difference can be interpreted as a causal impact of joining the FHG model provided that idiosyncratic deviations from the linear trend in outcomes do not vary systematically between treatment and comparison physicians except for the FHG impact.

The model is estimated by first differencing equation (12) to remove $\gamma_{i}$ and then applying a fixed effects estimator. In this estimation, we use weights from the matching step to account for the fact that some comparison physicians were matched to more than one treatment physician. We also use robust Huber-White standard errors clustered at the physician level to account for clustering and serial correlation. Because of the estimation error in the propensity score and the variation that it induces in the matching process, we bootstrap the estimate of $\delta$ and its standard error using the following procedure. We first draw a bootstrap sample with replacement from the full sample of 10,111 family physicians in 2002. We then estimate the propensity scores for this sample, using the same specification of the probability model as in the previous section, and use the nearest neighbor matching with replacement to select which comparison physicians to include in the final sample. This final sample is then matched to the full 1992-2008 period and the model is estimated as described above. The coefficients and standard errors for $\delta$ reported in the following sections are averages over 500 such replications. 


\section{Results}

\section{A. Initial Estimates}

Our initial estimates of the FHG impact are presented in Table 4. These estimates are based on the sample that excludes years with annual billings below $\mathrm{C} \$ 30,000$, a common income threshold used to identify physicians with the minimum attachment to the labour force. For comparison, we present results from the OLS model, the fixed effects model, and the correlated random trend model. These models progressively add more physicianspecific effects: the OLS model includes two observed fixed effects: the expected gain in 2002 and the number of working weekends and holidays in 2002; the fixed effects model includes a full set of physician fixed effects; and the correlated random trend includes both fixed effects and physician-specific linear trends. All three models indicate a positive and statistically significant difference in each outcome between the treatment and comparison physicians. The estimates from our preferred correlated random trend model suggest that joining the FHG model had a meaningful impact on physician behaviour, increasing the number of annual services, visits, and distinct patients by about 9.8, 7.1, and 6.3 percent, respectively. Based on the summary statistics in Table 3 and an average of 235 annual days of work, these changes are equivalent to about two to three additional weeks of work per year.

The estimates in Table 4 are based on samples selected using the nearest neighbor matching, where each treatment physician is matched to the single nearest comparison physician. In Table 5, we report results for the caliper matching that uses all comparison physicians that have a propensity score within a specified distance from the matched treatment physician. Theoretically, the choice between the two matching methods 
depends on the trade-off between bias and efficiency, as the caliper matching can improve standard errors relative to nearest neighbor matching, although at the cost of greater bias. In our application, this choice seems to be of little consequence. The point estimates from the correlated random trend model in Table 5 are within the 95 percent confidence interval for our initial estimates in Table 4. Based on these results, we continue to use the nearest neighbor matching in the remainder of our analysis.

\section{B. Inferring Causality using Multiple 'Experiments' and Dynamics of FHG Impact}

As mentioned previously, the estimates from the correlated random trend model have a causal interpretation provided that deviations from the linear trend in outcomes do not vary systematically between treatment and comparison physicians except for the FHG impact. While this assumption cannot be tested directly, we explore two complementary approaches to validate the causal impact of joining the FHG model.

The first approach is based on the fact that there were three main cohorts of physicians joining the FHG model, in 2003, 2004, and 2005. These cohorts present us with multiple 'experiments' to study the impact of joining the FHG model. While these experiments may not be independent of each other, the consistent results across cohorts support the causal interpretation of the FHG impact.

To explore this issue, we estimated the correlated random trend model for each treatment cohort separately. To facilitate the comparison of estimates across cohorts, we used the same group of comparison physicians in each model. The results are presented in Table 6. The estimated impact for each outcome is quite similar for the 2003 and 2004 cohorts and also to our initial results in Table 4, but the estimated impact for the 2005 
cohort is significantly larger. Overall, these results show some variation in the FHG impact across different cohorts, but the estimated impact remains relatively large and statistically significant for each treatment cohort.

The second approach to infer causality is to examine the dynamics of the estimated FHG impact. Specifically, we estimate the correlated random trend model for each year before and after the physician switches to the FHG model. If joining the FHG model has a causal impact, we expect to observe this impact only in years after the physician switches to the model but not in prior years. The results are shown in Table 7 and Figures 5 to $7^{22}$.

The results for the log of annual services and distinct patients closely confirm our prior expectations: the difference between the treatment and comparison physicians is insignificant in all years prior to joining the FHG model, but positive and significant in all years after joining the FHG model. The results for the log of annual visits are quite similar, with insignificant differences in almost all years prior to the switch and significant differences in all years after the switch. However, the difference is significant in the immediate year prior to the switch, suggesting that physicians may have started changing their practice in anticipation of joining the FHG model.

The results also indicate that the adjustment in practice profile was relatively quick, with a complete adjustment taking one to two years, and that the change in practice profile seems permanent, extending to the end of our sample period.

\footnotetext{
${ }^{22}$ For presentation purposes, we use a single indicator for observations that are six or more years prior to joining the FHG model. The results are very similar if we use a separate indicator for each of these years.
} 


\section{Alternative Samples}

Our initial estimates in Table 4 are based on a sample that includes years when physicians were in either FFS or FHG model and had at least C $\$ 30,000$ in annual FFS billings. In this section, we examine how this sample selection rule affects the interpretation of our results.

The first concern is that many physicians also receive clinical income from alternative payment plans (APPs), such as the Emergency Department Alternative Funding Arrangement. In general, services provided in these plans are not captured in the fee-for-service claims. This raises the concern that changes in physician behaviour in the FFS environment may reflect the impact of changes in the APPs rather than the FHG impact. For example, suppose that the incentives to provide services in the APPs substantially increased over the sample period and that only comparison physicians participate in the APPs. In this case, we may observe a reduction in the FFS claims for the comparison physicians, even though their total clinical services have not changed because they increased their services in the APPs. Using the FFS claims alone, we would incorrectly interpret the resulting differential in outcomes between the treatment and comparison physicians as the FHG impact.

To address this concern, we obtained data on the shadow billing claims that physicians use when providing services in the APPs. We then estimated the correlated random trend model using the sample that excludes years when physicians reported these claims. The results are presented in the first panel of Table 8 . The point estimates are very similar to our initial estimates in Table 4 . This result can perhaps be explained by the fact that both groups of physicians participate in the APPs and changes in the APPs 
affect both groups in a similar way. Based on these results, it appears that observed differences in outcomes between the treatment and comparison physicians cannot be entirely explained by physician participation in the APPs.

Another concern with the causal interpretation of the FHG impact is that our results may be driven by an idiosyncratic group of physicians who joined the FHG model but subsequently switched to a harmonized model. This concern is particularly important given that over 1,500 FHG physicians switched to the harmonized models between 2007 and 2008. In our previous results, we used samples that exclude years when physicians were not in the FFS or the FHG model. While this restriction facilitates the comparison of the FHG impact relative to the FFS model, the concern is that the estimated impact may reflect a higher productivity of physicians who were in the FHG model only temporarily.

To address this concern, we estimated the correlated random trend model using samples that exclude physicians who switched to a harmonized model at any point during the sample period. The results are presented in the second panel of Table 8 . The point estimates are slightly larger than our initial estimates in Table 8, suggesting that the impact was smaller for physicians who subsequently switched to a harmonized model. Importantly, the estimated impact for the included sample of physicians remains relatively large and statistically significant for each outcome.

The last panel of Table 8 presents the results using alternative income cut-offs (C\$0, C\$10,000K, C\$50,000, and $\mathrm{C} \$ 100,000)$ for deciding which observations to include in the estimation sample. These results show that the estimated FHG impact decreases monotonically as we use higher income cut-offs. For example, the estimated impact on annual services ranges between $0.14 \log$ points when we use no income cut-off to 0.0699 
$\log$ points when we use the highest cut-off of $\mathrm{C} \$ 100,000$. Similarly, the estimated impact for annual visits and distinct patients is more than twice as high when using no income cut-off compared to using the cut-off of $\mathrm{C} \$ 100,000$. These results indicate that the magnitude of the estimated FHG impact depends on the choice of specific income cutoff, but the impact remains positive and statistically significant regardless of which income cut-off is used.

\section{Estimates by Age, Gender, and Location}

The results reported in Table 4 represent the average impact of joining the FHG model. In this section, we examine how this impact varies for specific groups of treatment physicians defined by age, gender, and location of practice. In addition to two gender groups, we also sliced the sample into three age groups (less than 41 years, between 41

and 51 years, and over 51 years) and four regional groups (South East, Central, South West, and North).

The results, presented in Table 9, can be summarized by two main points. First, the estimates suggest that the impact is smaller for male physicians relative to female physicians and for physicians over 41 years relative to younger physicians. There is also some regional variation, but with no consistent pattern. However, the estimated impact seems reasonably stable across different physician groups. Second, the estimated impact is positive and statistically significant for each physician group and for each outcome, with the exception of the small Northern Ontario sample. These results suggest that the FHG impact was not limited to a particular age or sex group or to a particular region. 


\section{E. Decomposition of the FHG Impact on Services}

The results presented so far indicate that the FHG physicians provide more annual services than the comparable FFS physicians. In principle, this difference may arise because physicians work more hours or because their throughput per hour is higher. Unfortunately, data on hours of work is not available in our data and the throughput per hour cannot be calculated. Instead, we use the number of days per year when physicians submitted any FFS claims and calculate the throughput per day.

The results are presented in Table 10. The results indicate that $0.0936 \log$ point increase in services can be decomposed into 0.0498 log points in services per day and $0.0448 \log$ points in annual days. Therefore, the FHG physicians seem to both work more days and also provide more services per day.

The increase in services per day can come from several sources. Most obviously, it can come because physicians work more hours per day, perhaps because of the afterhours requirement. In addition, physicians in the group may combine resources to hire additional health professionals and therefore improve their productivity. There may also be significant team complementarities between physicians in the group. On the other hand, the increase in throughput can come because the FHG physicians refer more patients to specialists and/or because they treat less complex patients. Without further information, it is difficult to discriminate between these and related hypotheses. In the next section, we address a potentially negative FHG impact on referrals and patient complexity in more detail. 


\section{F. Impact on Referrals and Patient Selection}

Although our results indicate that the FHG physicians provide more services and visits and see more distinct patients, other considerations are also important. One such consideration is the impact of remuneration scheme on the referrals to specialists. From the perspective of public purse, the increased throughput of FHG physicians would obviously have less value if it came at the cost of increased referrals to specialists. To address this issue, we estimated the correlated random trend model using the log of referral rates as our dependent variable. The results are presented in the first panel of Table 11. The results indicate that the referral rates per service, visit, or distinct patient are all significantly lower for the treatment physicians relative to the comparison physicians, by about one to four percent. These results suggest that joining the FHG model does not have an unintended consequence of increasing the referral rates to specialists. The actual decline in the referral rates can perhaps be explained by the wider range of comprehensive care services that the FHG physicians are required to provide compared to the FFS physicians.

The other important consideration is the impact of remuneration scheme on the type of patients that family physicians see. Of particular concern is whether the increase in physician throughput comes at the cost of limiting access to more complex patients. To explore this issue, we calculated the average patient complexity for each physician using the following measure:

(13) $\frac{\sum v_{a s} m_{a s}}{\sum v_{a s}}$ 
where $v$ is the number of visits by patients in age group $a$ and of sex $s$, and $m$ is the agesex specific complexity modifier used by the Ministry of Health and Long-Term Care to adjust the Comprehensive Care Capitation fee.

We then estimated the correlated random trend model using the log of this measure of patient complexity as our dependent variable. The results are presented in the second panel of Table 11. The point estimate indicates that the average patient complexity is about three percent higher for the treatment physicians than for the comparison physicians. Therefore, to the extent that age and sex of patients appropriately capture patient complexity, it appears that the treatment physicians actually treat slightly more complex patients than the comparison physicians. This finding can perhaps be explained by the built-in incentives in the Comprehensive Care Capitation fee to enroll more complex types of patients.

\section{Implications and Conclusion}

Many recent primary health care reforms aim to improve access to physician services. This goal is particularly important in jurisdictions experiencing physician shortages which are sometimes exacerbated by an aging physician population, an increasing proportion of female physicians, and changing preferences and personal constraints of younger physicians ${ }^{23}$. In this paper, we show that the Family Health Group (FHG) model in Ontario offers a promising first step for achieving this goal. Specifically, we find that the FHG physicians provide more services and visits and see more patients than the comparable FFS physicians.

\footnotetext{
${ }^{23}$ For relative importance of these factors in explaining labour supply of Canadian family physicians, see Crossley et al. (2006).
} 
This improvement in the physician labour supply can be interpreted as a response to the incentive structure in the FHG model. The FHG model is basically a FFS model enhanced to include targeted fee increases, performance-based initiatives, extended hours, and patient enrolment. The targeted fee increases are expected to induce provision of physician services, as long as the substitution effect of these increases dominates the income effect. This impact is likely reinforced by the performance-based initiatives because they reward physicians for reaching specific service targets or providing special services. In addition, the extended-hours requirement may be particularly effective in raising the labour supply of physicians with strong preferences for work during regular hours. On the other hand, the capitation fee for enrolled patients is expected to reduce the physician labour supply due to its income effect.

Our results suggest that the net impact of these incentives is positive, and that the incentive structure in the FHG model affects the physician labour supply at the intensive margin. In the longer term, this incentive structure may also affect the extensive margin by increasing the level of compensation relative to specialists in Ontario and relative to family physicians in other jurisdictions.

Future research can build on our analysis in at least two ways. First, we document that the FHG model improves access to physician services, but it is also important to understand how the model affects the quality and cost of delivering primary health care. Second, our analysis focuses on the transition of physicians from the FFS model to the FHG model. Future research could consider the entire spectrum of payment models for primary care physicians, focusing on determinants of transition between the models and the impact of this transition on physician behaviour. 


\section{References}

Campbell S, Reeves D, Kontopantelis E, Middleton E, Sibbald B, Roland M. 2007. Quality of primary care in England with the introduction of pay for performance. New England Journal of Medicine 357(2):181-190.

Crossley TF, Hurley J, Jeon S. 2006. Physician labour supply in Canada: a cohort analysis. McMaster University, Department of Economics, Working Paper Series, 200602 .

Dehejia RH, Wahba S. 2002. Propensity-score matching methods for nonexperimental causal studies. The Review of Economics and Statistics 84(1): 151-161.

Devlin RA, Sarma S. 2008. Do physician remuneration schemes matter? The case of Canadian family physicians. Journal of Health Economics 25(7): 1168-1181.

Glazier RH, Klein-Geltnik J, Kopp A, Sibley LM. 2009. Capitation and enhanced feefor-service models for primary care reform: a population-based evaluation. Canadian Medical Association Journal 180(11): E72-E81.

Hippisley-Cox J, Vinogradova Y, Coupland C. 2007. Time Series Analysis for Selected Clinical Indicators from the Quality and Outcomes Framework 2001- 2006. Final Report for The Information Centre for health and social care.

Kantarevic J, Kralj B, Weinkauf D. 2008. Income Effects and Physician Labour Supply: Evidence from the Threshold System in Ontario. Canadian Journal of Economics, 41(4): 1262-1284.

Leuven E, Sianesi B. 2003. PSMATCH2: Stata module to perform full Mahalanobis and propensity score matching, common support graphing, and covariate imbalance testing. http://ideas.repec.org/c/boc/bocode/s432001.html. Version 3.1.5.

McGovern MP, Boroujerdi MA, Taylor MW, Williams DJ, Hannaford PC, Lefevre KE, Simpson CS. 2008. The effect of the UK incentive-based contract on the management of patients with coronary heart disease in primary care. Family Practice 25(1):33-39.

McGuire T, Pauly M. 1991. Physician response to fee changes with multiple payers. Journal of Health Economics 10, 385-410.

McGuire T. 2000. Physician agency. Handbook of Health Economics, Vol. 1, ed. A.L. Culyer and J.P. Newhouse (Amsterdam: North-Holland).

Rizzo J, Blumenthal D. 1994. Physician labor supply: do income effects matter? Journal of Health Economics 13: 433-453. 
Robert Graham Center. 2007. The patient centered medical home: history, seven core features, evidence and transformational change. Washington, DC. http://www.grahamcenter.org/online/etc/medialib/graham/documents/publications.

Rosenbaum PR, Rubin DB. 1983. The central role of the propensity score in observational studies for causal effects. Biometrika 70(1): 41-55.

Rosenbaum PR, Rubin DB. 1985. Constructing a control group using multivariate matched sampling methods that incorporate the propensity score. The American Statistician 39(1): 33-38.

Rosenthal MB. 2010. Impact of a medical home intervention on utilization and spending. Presentation at the American Economic Association meeting, Atlanta, January 3-5, 2010.

Rosser WW, Colwill JM, Kasperski J, Wilson L. 2010. Patient-centered medical homes in Ontario. New England Journal of Medicine 362(3): e7(1)-e7(3).

Russell GM, Dahrouge S, Hogg W, Geneau R, Muldoon L, Tuna M. 2009. Managing Chronic Disease in Ontario Primary Care: The Impact of Organizational Factors. Annals of Family Medicine 7: 309-318.

Smith PC, York N. 2004. Quality incentives: the case of U.K. general practitioners. Health Affairs 23(3): 112-118.

Steel N, Maisey S, Clark A, Fleetcroft R, Howe A. 2007. Quality of clinical primary care and targeted incentive payments: an observational study. British Journal of General Practice 57:449-454.

Sutton M, Elder R, Guthrie B, Watt G. 2010. Record rewards: the effects of targeted quality incentives on the recording of risk factors by primary care providers. Health Economics 19: 1-13.

Tahrani AA, McCarthy M, Godson J, Taylor S, Slater H, Capps N, Moulik P, Macleod AF. 2007. Diabetes care and the new GMS contract: the evidence for a whole county. British Journal of General Practice 57:483-485.

Tai-Seale M, Rice T, Sally S. 1998. 'Volume responses to Medicare payment reductions with multiple payers: a test of the McGuire-Pauly model. Health Economics 7: 199-219.

Wooldridge JM. 2005. Fixed-Effects and Related Estimators for Correlated RandomCoefficient and Treatment-Effect Panel Data Models. The Review of Economics and Statistics 87(2): 385-390.

Yip W. 1998. Physician response to Medicare fee reductions: changes in the volume of coronary artery bypass graft surgeries in the Medicare and private sectors. Journal of Health Economics 17: 675-699. 


\section{Appendix}

Comparative Statics when the After-Hours is Not Binding

The first-order necessary conditions for the interior solution to the problem described by (1)-(4) are:

$u_{C} p_{1}-t_{1} u_{l}=0$

$u_{C} p_{2}-t_{2} u_{l}+u_{2}=0$

Totally differentiating these conditions and rearranging, we have

$$
\begin{gathered}
{\left[\begin{array}{cc}
u_{c c} p_{1}^{2}+u_{l l} t_{1}^{2} & u_{c c} p_{1} p_{2}+u_{l l} t_{1} t_{2} \\
u_{c c} p_{1} p_{2}+u_{l l} t_{1} t_{2} & u_{c c} p_{2}^{2}+u_{l l} t_{2}^{2}+u_{22}
\end{array}\right]\left[\begin{array}{c}
d x_{1} \\
d x_{2}
\end{array}\right]=} \\
-\left[\begin{array}{ccc}
u_{c c} p_{1} x_{1}+u_{c} & u_{c c} p_{1} x_{2} & u_{c c} p_{1} \\
u_{c c} p_{2} x_{1} & u_{c c} p_{1} x_{1}+u_{c} & u_{c c} p_{2}
\end{array}\right]\left[\begin{array}{c}
d p_{1} \\
d p_{2} \\
d m
\end{array}\right]
\end{gathered}
$$

Let $D$ denote the determinant of the matrix of coefficients associated with changes in the endogenous variables. By the second-order condition, $D>0$.

With negligible income effects $\left(u_{c c} \rightarrow 0\right)$, by Cramer's rule we have:

$\partial x_{1} / \partial p_{1}=-u_{c}\left(u_{l l} t_{2}^{2}+u_{22}\right) / D>0$

$\partial x_{2} / \partial p_{2}=-u_{c} u_{l l} t_{1}^{2} / D>0$

$\partial x_{i} / \partial p_{j}=u_{c} u_{l l} t_{1} t_{2} / D<0$

The total change in $x_{1}$ and $x_{2}$ is then given by:

$\Delta\left(x_{1}+x_{2}\right) \propto u_{l l}\left(t_{2}-t_{1}\right)\left[t_{1} \Delta p_{2}-t_{2} \Delta p_{1}\right]-u_{22} \Delta p_{1}$

where the factor of proportionality is $u_{c} D$.

We want to show that a sufficient condition for $\Delta\left(x_{1}+x_{2}\right) \geq 0$ is that $t_{2} \leq t_{1}$. First, note that $-u_{22} \Delta p_{1} \geq 0$ by the model assumption. Second, $t_{1} \Delta p_{2}-t_{2} \Delta p_{1}=a b\left(t_{1} k_{2} p_{2}-t_{2} k_{1} p_{1}\right)$. From the first-order conditions, we have that $p_{1}=p_{2} t_{1} / t_{2}+u_{2} t_{1} / t_{2} u_{C}$. Therefore, $t_{1} k_{2} p_{2}-t_{2} k_{1} p_{1}$ can be expressed as $t_{1} p_{2}\left(k_{2}-k_{1}\right)-k_{1} t_{1} u_{2} / u_{C}$. This term is positive because in the FHG model $k_{2}=0.2>k_{1}=0.1$. Therefore, $t_{1} \Delta p_{2}-t_{2} \Delta p_{1}>0$. Lastly, provided that $t_{2} \leq t_{1}$, we have that $\Delta\left(x_{1}+x_{2}\right) \geq 0$. 


\section{Comparative Statics when the After-Hours is Binding}

The first-order necessary conditions for the corner solution to the problem to the problem described by (1)-(4) are:

$u_{C} p_{1}-t_{1} u_{l}=0$

$u_{C} p_{2}-t_{2} u_{l}+u_{2}+\lambda=0$

$x_{2}-x_{\min }=0$

Totally differentiating these conditions and rearranging, we have

$$
\begin{aligned}
& {\left[\begin{array}{ccc}
u_{c c} p_{1}^{2}+u_{l l} t_{1}^{2} & u_{c c} p_{1} p_{2}+u_{l l} t_{1} t_{2} & 0 \\
u_{c c} p_{1} p_{2}+u_{l l} t_{1} t_{2} & u_{c c} p_{2}^{2}+u_{l l} t_{2}^{2}+u_{22} & 1 \\
0 & 1 & 0
\end{array}\right]\left[\begin{array}{c}
d x_{1} \\
d x_{2} \\
d \lambda
\end{array}\right]=} \\
& -\left[\begin{array}{cccc}
u_{c c} p_{1} x_{1}+u_{C} & u_{c c} p_{1} x_{2} & u_{c c} p_{1} & 0 \\
u_{c c} p_{2} x_{1} & u_{c c} p_{1} x_{1}+u_{c} & u_{c c} p_{2} & 0 \\
0 & 0 & 0 & 1
\end{array}\right]\left[\begin{array}{c}
d p_{1} \\
d p_{2} \\
d m \\
d x_{\min }
\end{array}\right]
\end{aligned}
$$

Let $J$ denote the determinant of the matrix of coefficients associated with changes in the endogenous variables. By the second-order condition, $J>0$.

With negligible income effects $\left(u_{c c} \rightarrow 0\right)$, by Cramer's rule we have:

$\partial x_{1} / \partial p_{1}=u_{c} / J>0$

$\partial x_{2} / \partial p_{2}=-u_{l l} t_{1}^{2} / J>0$

$\partial x_{i} / \partial p_{j}=0$

$\partial x_{1} / \partial x_{\min }=u_{l l} t_{1} t_{2} / J<0$

$\partial x_{2} / \partial x_{\min }=-u_{l l} t_{1}^{2} / J>0$

The total change in $x_{1}$ and $x_{2}$ is then given by:

$\Delta\left(x_{1}+x_{2}\right) \propto u_{C} \Delta p_{1}-u_{l l} t_{1}^{2} \Delta p_{2}+u_{l l}\left(t_{1} t_{2}-t_{1}^{2}\right) \Delta x_{\min }$

where the factor of proportionality is $J$.

The first two terms on the right-hand side are non-negative. The third term is also nonnegative, provided $t_{2} \leq t_{1}$. Therefore, we have that $\Delta\left(x_{1}+x_{2}\right) \geq 0$. 
Table 1.

Primary Care Compensation Models in Ontario, January 2010

\begin{tabular}{ccc}
\hline Compensation Model & Physicians & $\begin{array}{c}\text { \% of Family } \\
\text { Physicians }\end{array}$ \\
\hline Patient Enrolment Models & & \\
\hline Harmonized (Blended Capitation) & & \\
$\quad$ Family Health Network & 430 & $3.8 \%$ \\
Family Health Organization & 2,839 & $25.0 \%$ \\
Other Harmonized & 311 & $2.7 \%$ \\
Non-Harmonized (Enhanced FFS) & & \\
Family Health Group & 3,414 & $30.1 \%$ \\
Comprehensive Care Model & 318 & $2.8 \%$ \\
Other Patient Enrolment Models & 235 & $2.1 \%$ \\
& & \\
Fee-for-Service (FFS) Model & 3,796 & $33.5 \%$ \\
\hline
\end{tabular}


Table 2.

Comparison of Elements in FFS and FHG Models

\begin{tabular}{lcc}
\hline & FFS Model & FHG Model \\
\hline Organizational Elements & 1 & \\
\hline $\begin{array}{l}\text { Group Size } \\
\text { Patient Enrolment } \\
\text { After-Hours Requirement }\end{array}$ & No & $\geq 3$ \\
\hline $\begin{array}{l}\text { Compensation Elements } \\
\text { FFS Billings }\end{array}$ & Yes \\
FFS Premiums & $100 \%$ & Yes \\
& No CC Premium & $10 \%$ CC Premium \\
CCC Fee & No AH Premium & $20 \%$ AH Premium \\
Incentives and Bonuses & No & Yes \\
& No & Yes \\
\hline
\end{tabular}

NOTE. FFS = Fee-for-Service; FHG = Family Health Group; CCC = Comprehensive Care Capitation; $\mathrm{CC}=$ Comprehensive Care; $\mathrm{AH}=$ After-hours. Incentives and bonuses include preventive care bonuses (pap smears, mammograms, childhood immunizations, flu shots, colorectal screening), special payments (obstetrical deliveries, hospital services, palliative care, prenatal care, home visits), chronic disease management fees (diabetes, congestive heart failure), and incentives to enroll unattached patients. 
Table 3.

Summary Statistics, 2002

\begin{tabular}{|c|c|c|c|}
\hline & \multirow{2}{*}{$\begin{array}{c}\text { Treatment } \\
\text { (FHG) } \\
\text { Group }\end{array}$} & \multicolumn{2}{|c|}{$\begin{array}{c}\text { Comparison } \\
\text { (Never FHG) Group }\end{array}$} \\
\hline & & $\begin{array}{c}\text { Full } \\
\text { Sample }\end{array}$ & $\begin{array}{l}\text { Matched } \\
\text { Sample }\end{array}$ \\
\hline Number of Physicians & 5,260 & 4,851 & 1,734 \\
\hline \multicolumn{4}{|l|}{ Covariates: } \\
\hline Average Age & 46.5 & $50.3^{*}$ & 46.4 \\
\hline Percent Male & 0.65 & $0.70^{*}$ & 0.66 \\
\hline Percent in Toronto Central Region & 0.12 & $0.18^{*}$ & 0.13 \\
\hline Expected Income Gain (C\$) & 42,844 & $18,222^{*}$ & 42,629 \\
\hline Working Weekends and Holidays & 31.6 & $21.0^{*}$ & 32.1 \\
\hline \multicolumn{4}{|l|}{ Outcomes: } \\
\hline Log of Annual Services & 8.92 & $7.83^{*}$ & 8.93 \\
\hline Log of Annual Visits & 8.65 & $7.33^{*}$ & 8.65 \\
\hline Log of Annual Distinct Patients & 7.49 & $6.37^{*}$ & 7.49 \\
\hline \multicolumn{4}{|c|}{$\begin{array}{l}\text { NOTE. FHG = Family Health Group. }{ }^{*} \text { indicates that the difference from the FHG group } \\
\text { is significant at } 0.05 \text { level using the two-tail t-test. The t-tests are based on a regression } \\
\text { of each covariate on the treatment indicator. Before matching, this is an unweighted } \\
\text { regression on the whole sample; after matching, the regression is weighted using the } \\
\text { number of times each comparison physician is matched to a physician in the treatment } \\
\text { group. }\end{array}$} \\
\hline
\end{tabular}


Table 4.

Impact of Joining FHG on Physician Productivity (Sample Selection Using Nearest Neighbor Matching)

\begin{tabular}{lcccc}
\hline & & \multicolumn{3}{c}{ Dependent Variable } \\
\cline { 5 - 5 } Specification & $\begin{array}{c}\text { Sample Size } \\
\text { [Physicians] }\end{array}$ & Log of Services & Log of Visits & Log of Patients \\
\hline \multirow{2}{*}{ OLS } & 95,890 & 0.1107 & 0.1012 & 0.0911 \\
& {$[6,938]$} & $(0.0256)$ & $(0.0251)$ & $(0.0344)$ \\
Fixed Effects & 95,890 & 0.1374 & 0.1209 & 0.1167 \\
& {$[6,938]$} & $(0.0219)$ & $(0.0212)$ & $(0.0237)$ \\
Correlated Random Trend & 89,741 & 0.0936 & 0.0682 & 0.0610 \\
& {$[6,929]$} & $(0.0090)$ & $(0.0090)$ & $(0.0088)$ \\
\hline
\end{tabular}

NOTE. FHG = Family Health Group. Bootstrap standard errors in parentheses. The OLS model includes age, age squared, male, age-male interaction term, expected income gain in 2002, number of working holidays and weekends in 2002, 14 regional indicators, and 17 year effects. The fixed-effect model and the correlated random trend model include 14 regional indicators and 17 year effects. The sample excludes observations with annual fee-for-service billings below $\mathrm{C} \$ 30 \mathrm{~K}$. 
Table 5.

Impact of Joining FHG on Physician Productivity (Sample Selection Using Caliper Matching)

\begin{tabular}{lcccc}
\hline & & \multicolumn{3}{c}{ Dependent Variable } \\
\cline { 3 - 5 } Specification & $\begin{array}{c}\text { Sample Size } \\
\text { [Physicians] }\end{array}$ & Log of Services & Log of Visits & Log of Patients \\
\hline \multirow{2}{*}{ Distance $=0.0005$} & 86,771 & 0.0975 & 0.0723 & 0.0649 \\
& & & & \\
Distance $=0.0001$ & 52,737 & $0.0095)$ & $(0.0095)$ & $(0.0093)$ \\
& {$[4,103]$} & $(0.0139)$ & $(0.0141)$ & 0.0657 \\
Distance $=0.00005$ & 34,401 & 0.0998 & 0.0763 & $0.068)$ \\
& {$[2,704]$} & $(0.0184)$ & $(0.0187)$ & $(0.0184)$ \\
\hline
\end{tabular}

NOTE. FHG = Family Health Group. Bootstrap standard errors in parentheses. Estimates from correlated random trend model which also includes 14 regional indicators and 17 year effects. The sample excludes observations with annual fee-for-service billings below C\$30K. 
Table 6.

Impact by Cohort

\begin{tabular}{|c|c|c|c|c|}
\hline \multirow[b]{2}{*}{ Sample } & \multirow{2}{*}{$\begin{array}{l}\text { Sample Size } \\
\text { [Physicians] }\end{array}$} & \multicolumn{3}{|c|}{ Dependent Variable } \\
\hline & & Log of Services & Log of Visits & Log of Patients \\
\hline 2003 Cohort & $\begin{array}{l}44,194 \\
{[3,633]}\end{array}$ & $\begin{array}{c}0.0875 \\
(0.0192)\end{array}$ & $\begin{array}{c}0.0793 \\
(0.0188)\end{array}$ & $\begin{array}{c}0.0635 \\
(0.0177)\end{array}$ \\
\hline 2004 Cohort & $\begin{array}{l}39,002 \\
{[3,073]}\end{array}$ & $\begin{array}{c}0.0857 \\
(0.0213)\end{array}$ & $\begin{array}{c}0.0770 \\
(0.0204)\end{array}$ & $\begin{array}{c}0.0777 \\
(0.0196)\end{array}$ \\
\hline 2005 Cohort & $\begin{array}{l}39,721 \\
{[3,089]}\end{array}$ & $\begin{array}{c}0.1799 \\
(0.0251)\end{array}$ & $\begin{array}{c}0.1173 \\
(0.0249)\end{array}$ & $\begin{array}{c}0.1036 \\
(0.0245)\end{array}$ \\
\hline
\end{tabular}

NOTE. Each cohort regression uses physicians who switched to the Family Health Group (FHG) in a given year as the treatment group and physicians who never switched to the FHG as the comparison group. Bootstrap standard errors in parentheses. Estimates from correlated random trend model which also includes 14 regional indicators and 17 year effects. The sample excludes observations with annual fee-for-service billings below C\$30K. 
Table 7.

Impact by Year

\begin{tabular}{lccc}
\hline & \multicolumn{3}{c}{ Dependent Variable } \\
\cline { 2 - 4 } Year & Log of Services & Log of Visits & Log of Patients \\
\hline \multirow{3}{*}{ Year $\leq t-6$} & 0.0001 & 0.0060 & 0.0181 \\
& $(0.0189)$ & $(0.0173)$ & $(0.0226)$ \\
Year $t-5$ & 0.0080 & 0.0103 & 0.0302 \\
& $(0.0159)$ & $(0.0148)$ & $(0.0232)$ \\
Year $t-4$ & 0.0042 & 0.0084 & 0.0234 \\
& $(0.0152)$ & $(0.0141)$ & $(0.0233)$ \\
Year $t-3$ & -0.0001 & 0.0076 & 0.0126 \\
& $(0.0150)$ & $(0.0138)$ & $(0.0239)$ \\
Year $t-2$ & 0.0093 & 0.0219 & 0.0229 \\
& $(0.0158)$ & $(0.0148)$ & $(0.0254)$ \\
Year $t-1$ & 0.0298 & 0.0500 & 0.0431 \\
& $(0.0180)$ & $(0.0171)$ & $(0.0276)$ \\
Year of Switch & 0.0920 & 0.0917 & 0.0836 \\
& $(0.0226)$ & $(0.0217)$ & $(0.0319)$ \\
Year $t+1$ & 0.1357 & 0.1180 & 0.1030 \\
Year $t+2$ & $(0.0264)$ & $(0.0256)$ & $(0.0361)$ \\
& 0.1238 & 0.1185 & 0.1011 \\
Year $t+3$ & $(0.0310)$ & $(0.0303)$ & $(0.0411)$ \\
& 0.1203 & 0.1139 & 0.0957 \\
Year $t+4$ & $(0.0345)$ & $(0.0343)$ & $(0.0451)$ \\
& 0.1004 & 0.0915 & 0.0932 \\
Year $t+5$ & $(0.0385)$ & $(0.0381)$ & $(0.0488)$ \\
& 0.0997 & 0.0904 & 0.1308 \\
& $(0.0450)$ & $(0.0448)$ & $(0.0553)$ \\
& & & \\
\hline
\end{tabular}

NOTE. Bootstrap standard errors in parentheses. Estimates from correlated random trend model which also includes 14 regional indicators and 17 year effects. The sample size is 89,741 observations (6,929 distinct physicians). The sample excludes observations with annual fee-for-service billings below $\mathrm{C} \$ 30 \mathrm{~K}$ 
Table 8.

Alternative Samples

\begin{tabular}{|c|c|c|c|c|}
\hline \multirow[b]{2}{*}{ Sample } & \multirow{2}{*}{$\begin{array}{l}\text { Sample Size } \\
\text { [Physicians] }\end{array}$} & \multicolumn{3}{|c|}{ Dependent Variable } \\
\hline & & Log of Services & Log of Visits & Log of Patients \\
\hline $\begin{array}{l}\text { Excluding Years with } \\
\text { Shadow Claims }\end{array}$ & $\begin{array}{l}86,362 \\
{[6,865]}\end{array}$ & $\begin{array}{c}0.0892 \\
(0.0092)\end{array}$ & $\begin{array}{l}0.0613 \\
(0.0091)\end{array}$ & $\begin{array}{c}0.0568 \\
(0.0086)\end{array}$ \\
\hline $\begin{array}{l}\text { Excluding Switchers to } \\
\text { Harmonized Models }\end{array}$ & $\begin{array}{l}63,910 \\
{[4,659]}\end{array}$ & $\begin{array}{l}0.1099 \\
(0.0115)\end{array}$ & $\begin{array}{l}0.0789 \\
(0.0114)\end{array}$ & $\begin{array}{c}0.0704 \\
(0.0110)\end{array}$ \\
\hline \multicolumn{5}{|l|}{ Income Restrictions: } \\
\hline No Restriction & $\begin{array}{l}92,748 \\
{[6,981]}\end{array}$ & $\begin{array}{l}0.1400 \\
(0.0127)\end{array}$ & $\begin{array}{c}0.1158 \\
(0.0129)\end{array}$ & $\begin{array}{c}0.1014 \\
(0.0120)\end{array}$ \\
\hline$>C \$ 10,000$ & $\begin{array}{l}91,512 \\
{[6,964]}\end{array}$ & $\begin{array}{l}0.1124 \\
(0.0101)\end{array}$ & $\begin{array}{l}0.0873 \\
(0.0101)\end{array}$ & $\begin{array}{c}0.0753 \\
(0.0095)\end{array}$ \\
\hline$>C \$ 50,000$ & $\begin{array}{l}87,818 \\
{[6,879]}\end{array}$ & $\begin{array}{l}0.0823 \\
(0.0084)\end{array}$ & $\begin{array}{l}0.0566 \\
(0.0083)\end{array}$ & $\begin{array}{c}0.0541 \\
(0.0083)\end{array}$ \\
\hline > C $\$ 100,000$ & $\begin{array}{l}80,140 \\
{[6,652]}\end{array}$ & $\begin{array}{c}0.0699 \\
(0.0078)\end{array}$ & $\begin{array}{c}0.0441 \\
(0.0076)\end{array}$ & $\begin{array}{c}0.0434 \\
(0.0076)\end{array}$ \\
\hline
\end{tabular}

NOTE. Shadow claims = claims that are not paid at full fee-for-service (FFS) value that physicians use in alternative payment plans. Harmonized models = primary care blended capitation models. Bootstrap standard errors in parentheses. Estimates from correlated random trend model which also includes 14 regional indicators and 17 year effects. The regressions using samples that exclude years with shadow claims and switchers to harmonized models exclude observations with annual fee-for-service billings below C\$30K. 
Table 9.

Impact by Age, Gender, and Location

\begin{tabular}{|c|c|c|c|c|}
\hline \multirow[b]{2}{*}{ Sample } & \multirow{2}{*}{$\begin{array}{l}\text { Sample Size } \\
\text { [Physicians] }\end{array}$} & \multicolumn{3}{|c|}{ Dependent Variable } \\
\hline & & Log of Services & Log of Visits & Log of Patients \\
\hline Males & $\begin{array}{l}61,985 \\
{[4,608]}\end{array}$ & $\begin{array}{c}0.0872 \\
(0.0107)\end{array}$ & $\begin{array}{c}0.0621 \\
(0.0107)\end{array}$ & $\begin{array}{c}0.0575 \\
(0.0105)\end{array}$ \\
\hline Females & $\begin{array}{l}27,756 \\
{[2,321]}\end{array}$ & $\begin{array}{c}0.1068 \\
(0.0163)\end{array}$ & $\begin{array}{c}0.0802 \\
(0.0164)\end{array}$ & $\begin{array}{c}0.0679 \\
(0.0155)\end{array}$ \\
\hline Age in 2002: < 41 & $\begin{array}{l}24,513 \\
{[2,324]}\end{array}$ & $\begin{array}{c}0.0990 \\
(0.0191)\end{array}$ & $\begin{array}{c}0.0776 \\
(0.0190)\end{array}$ & $\begin{array}{c}0.0684 \\
(0.0181)\end{array}$ \\
\hline Age in 2002: 41 to 51 & $\begin{array}{l}28,952 \\
{[2,093]}\end{array}$ & $\begin{array}{c}0.0842 \\
(0.0134)\end{array}$ & $\begin{array}{c}0.0632 \\
(0.0134)\end{array}$ & $\begin{array}{c}0.0558 \\
(0.0133)\end{array}$ \\
\hline Age in 2002: > 51 & $\begin{array}{l}36,276 \\
{[2,512]}\end{array}$ & $\begin{array}{c}0.0869 \\
(0.0123)\end{array}$ & $\begin{array}{c}0.0539 \\
(0.0121)\end{array}$ & $\begin{array}{c}0.0502 \\
(0.0122)\end{array}$ \\
\hline South East Ontario & $\begin{array}{l}19,772 \\
{[1,577]}\end{array}$ & $\begin{array}{c}0.0630 \\
(0.0160)\end{array}$ & $\begin{array}{c}0.0542 \\
(0.0159)\end{array}$ & $\begin{array}{c}0.0504 \\
(0.0173)\end{array}$ \\
\hline Central Ontario & $\begin{array}{l}37,502 \\
{[2,792]}\end{array}$ & $\begin{array}{c}0.1124 \\
(0.0128)\end{array}$ & $\begin{array}{c}0.0703 \\
(0.0125)\end{array}$ & $\begin{array}{c}0.0580 \\
(0.0115)\end{array}$ \\
\hline South West Ontario & $\begin{array}{l}24,668 \\
{[1,898]}\end{array}$ & $\begin{array}{c}0.1007 \\
(0.0205)\end{array}$ & $\begin{array}{c}0.0799 \\
(0.0204)\end{array}$ & $\begin{array}{c}0.0729 \\
(0.0204)\end{array}$ \\
\hline Northern Ontario & $\begin{array}{l}7,799 \\
{[682]}\end{array}$ & $\begin{array}{c}0.0672 \\
(0.0342)\end{array}$ & $\begin{array}{c}0.0614 \\
(0.0349)\end{array}$ & $\begin{array}{c}0.0729 \\
(0.0329)\end{array}$ \\
\hline
\end{tabular}

NOTE. Bootstrap standard errors in parentheses. Estimates from correlated random trend model which also includes 14 regional indicators and 17 year effects. The sample excludes observations with annual fee-forservice billings below $\mathrm{C} \$ 30 \mathrm{~K}$. 
Table 10.

Decomposition of FHG Impact on Annual Services

\begin{tabular}{lcc}
\hline Dependent Variable & $\begin{array}{c}\text { Coefficient on } \\
\text { FHG Indicator }\end{array}$ & $\begin{array}{c}\text { Bootstrap } \\
\text { Standard Error }\end{array}$ \\
\hline Log of Services & 0.0936 & $(0.0090)$ \\
\hline Log of Services per Day & 0.0498 & $(0.0046)$ \\
Log of Days & 0.0448 & $(0.0067)$ \\
\hline
\end{tabular}

NOTE. Estimates from correlated random trend model which also includes 14 regional indicators and 17 year effects. The sample size is 89,741 observations (6,929 distinct physicians). The sample excludes observations with annual fee-for-service billings below $\mathrm{C} \$ 30 \mathrm{~K}$. 
Table 11.

Impact on Referrals and Patient Complexity

\begin{tabular}{lcc}
\hline Dependent Variable & $\begin{array}{c}\text { Coefficient on } \\
\text { FHG Indicator }\end{array}$ & $\begin{array}{c}\text { Bootstrap } \\
\text { Standard Error }\end{array}$ \\
\hline Log of Referrals per Service & -0.0421 & $(0.0086)$ \\
Log of Referrals per Visit & -0.0169 & $(0.0081)$ \\
& & \\
Log of Referrals per Patient & -0.0098 & $(0.0092)$ \\
\hline & 0.0278 & $(0.0019)$ \\
\hline $\begin{array}{l}\text { Log of Complexity Modifier } \\
\text { NOTE. Estimates from correlated random trend model which also } \\
\text { includes } 14 \text { regional indicators and } 17 \text { year effects. The sample size is } \\
89,741 \text { observations }(6,929 \text { distinct physicians). The sample excludes } \\
\text { observations with annual fee-for-service billings below C } \$ 30 \mathrm{~K} .\end{array}$
\end{tabular}




\section{Figure 1}

Distribution of Physicians on Estimated Propensity Score

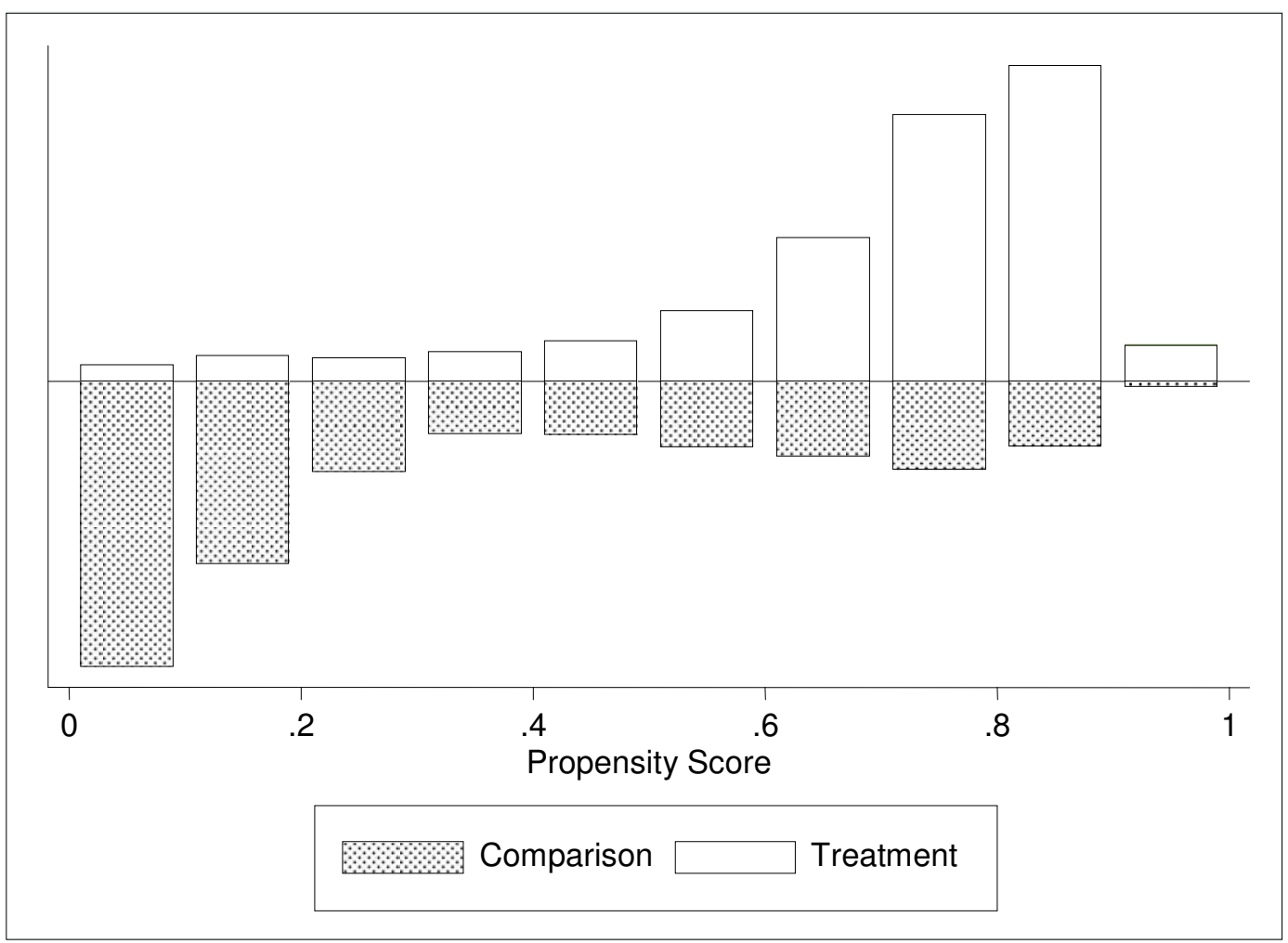


Figure 2

Log of Annual Services per Physician, 1992-2008

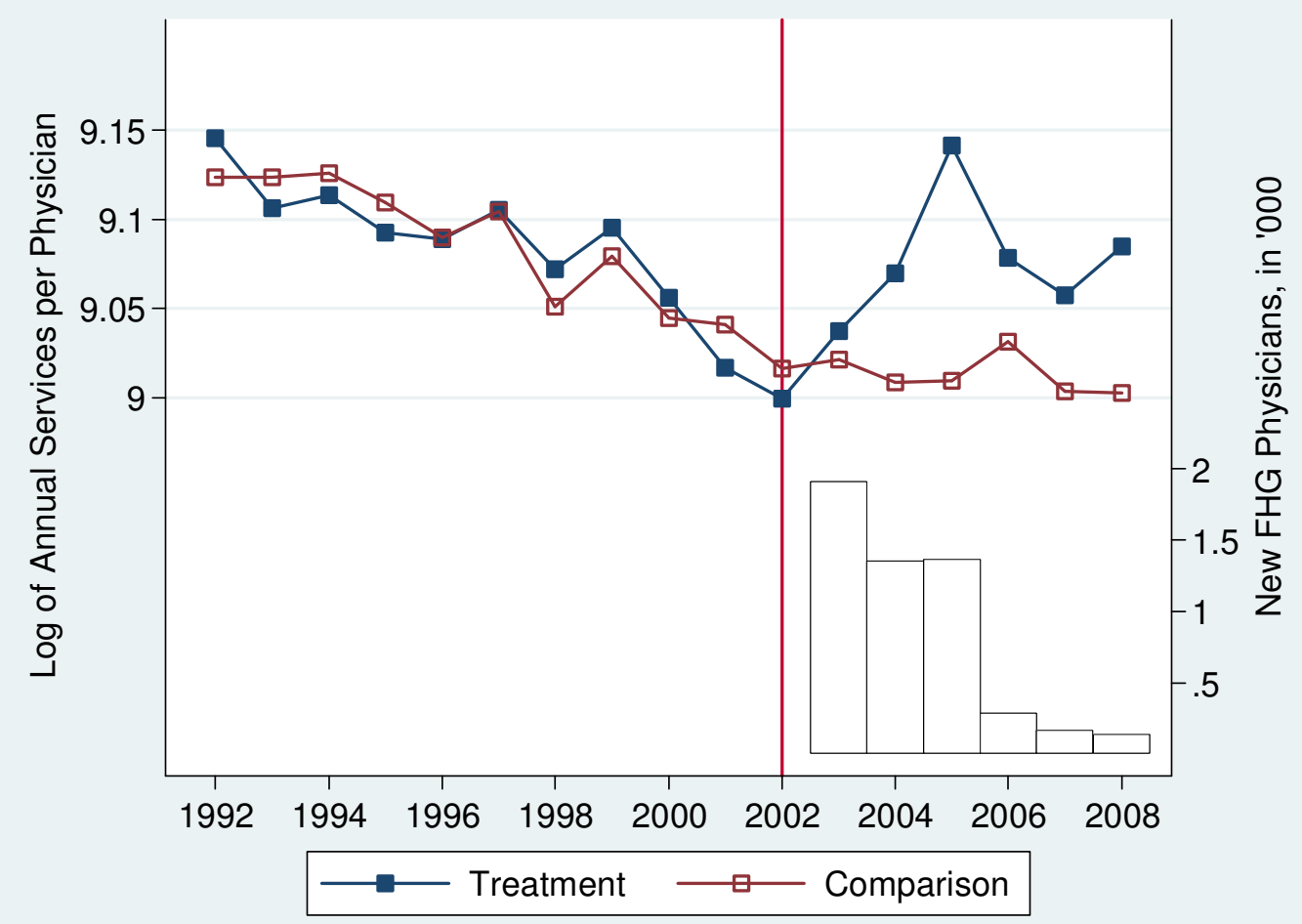


Figure 3

Log of Annual Visits per Physician, 1992-2008

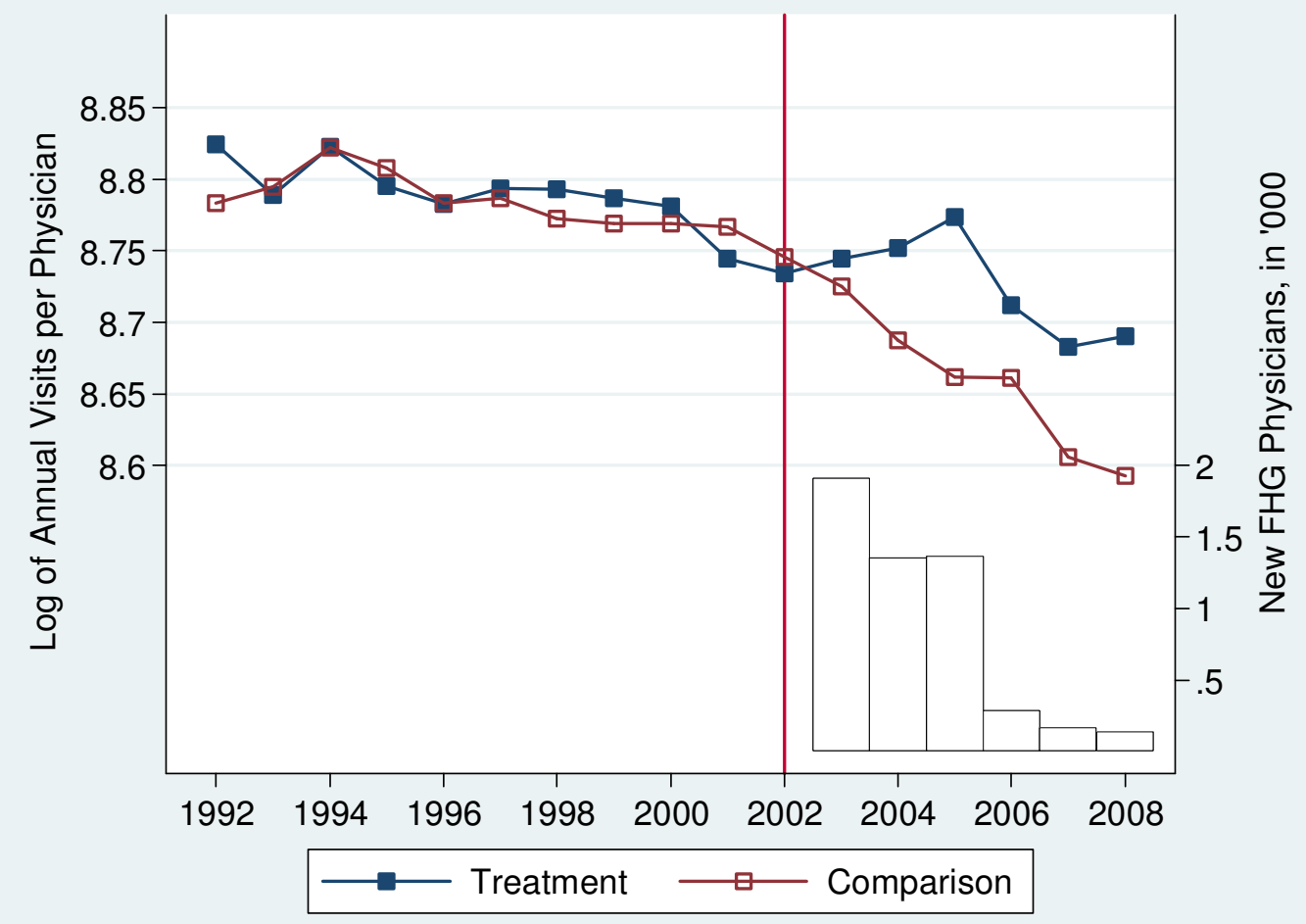


Figure 4

Log of Annual Distinct Patients per Physician, 1992-2008

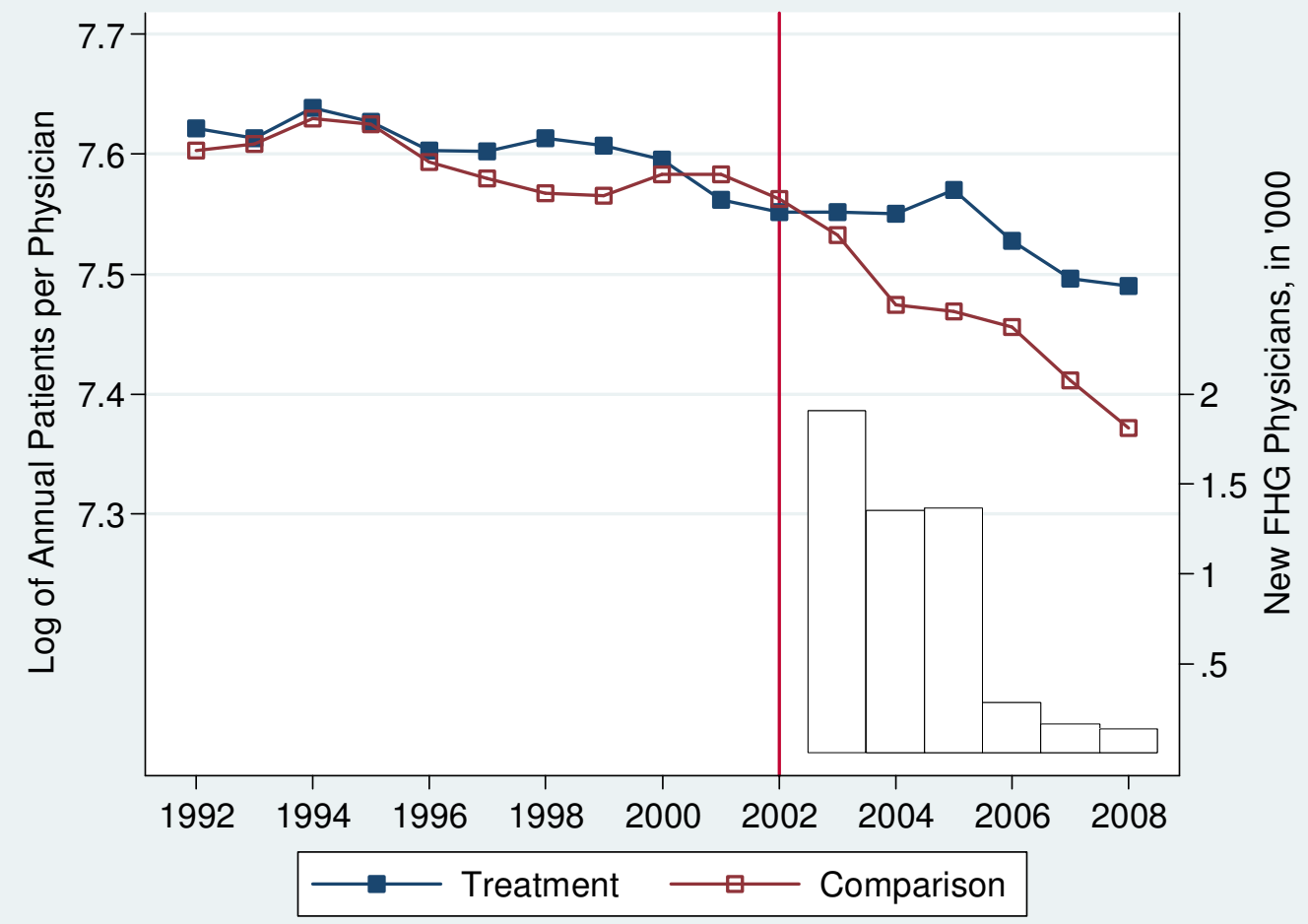


Figure 5

95 Percent Confidence Interval of FHG Impact by Lead and Lag Years Log of Annual Services per Physician

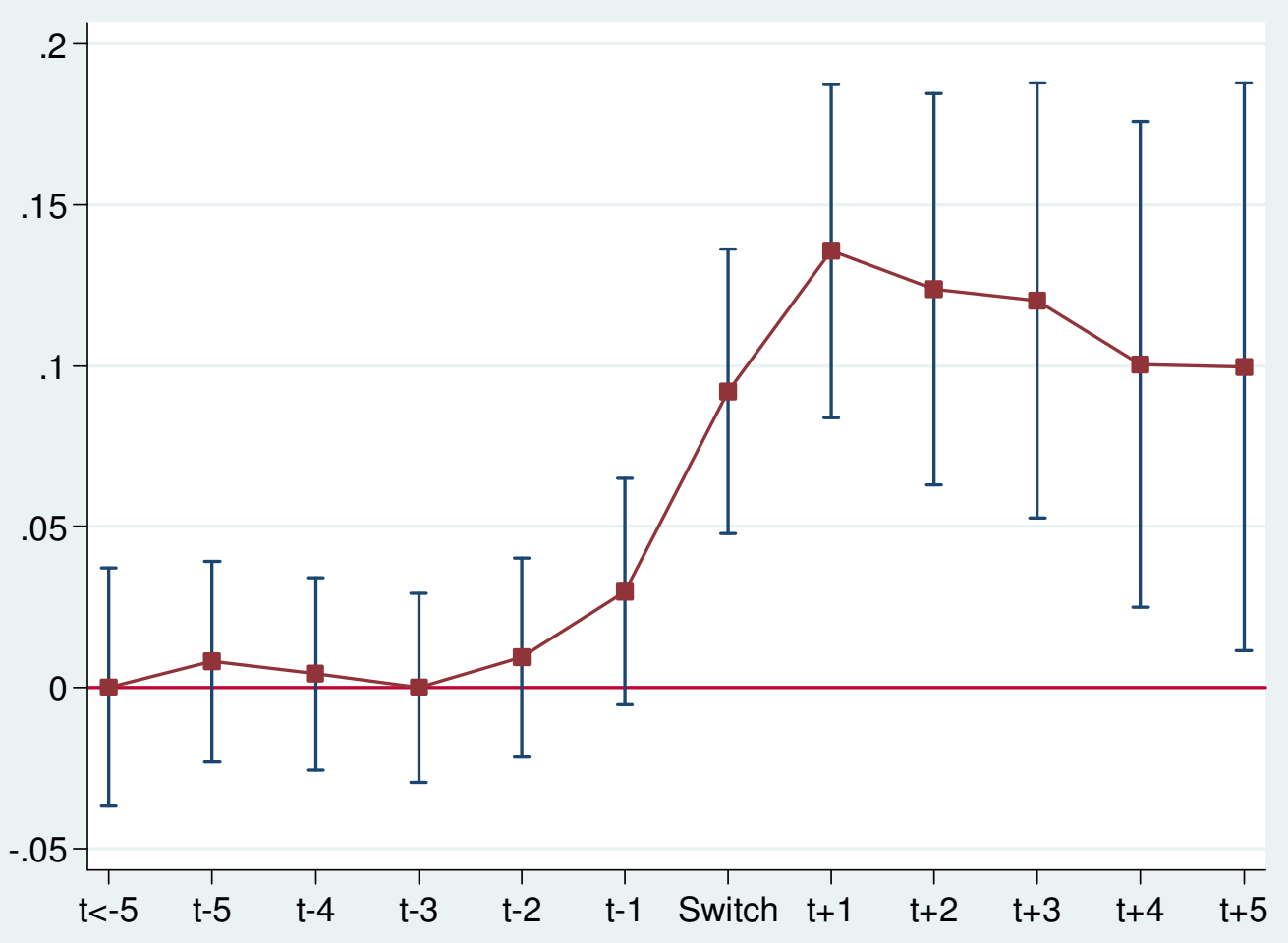


Figure 6

95 Percent Confidence Interval of FHG Impact by Lead and Lag Years Log of Annual Visits per Physician

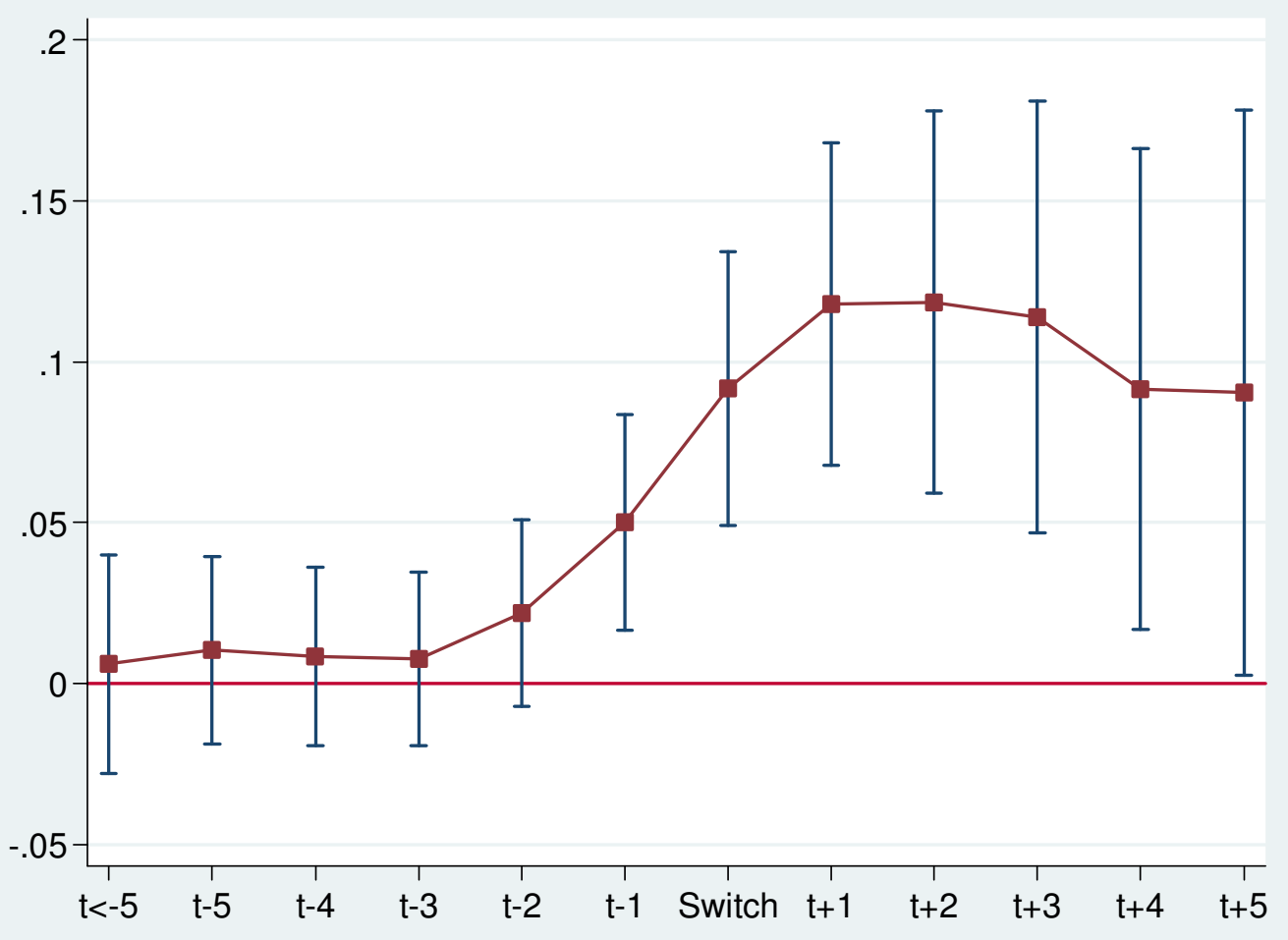


Figure 7

95 Percent Confidence Interval of FHG Impact by Lead and Lag Years Log of Annual Distinct Patients per Physician

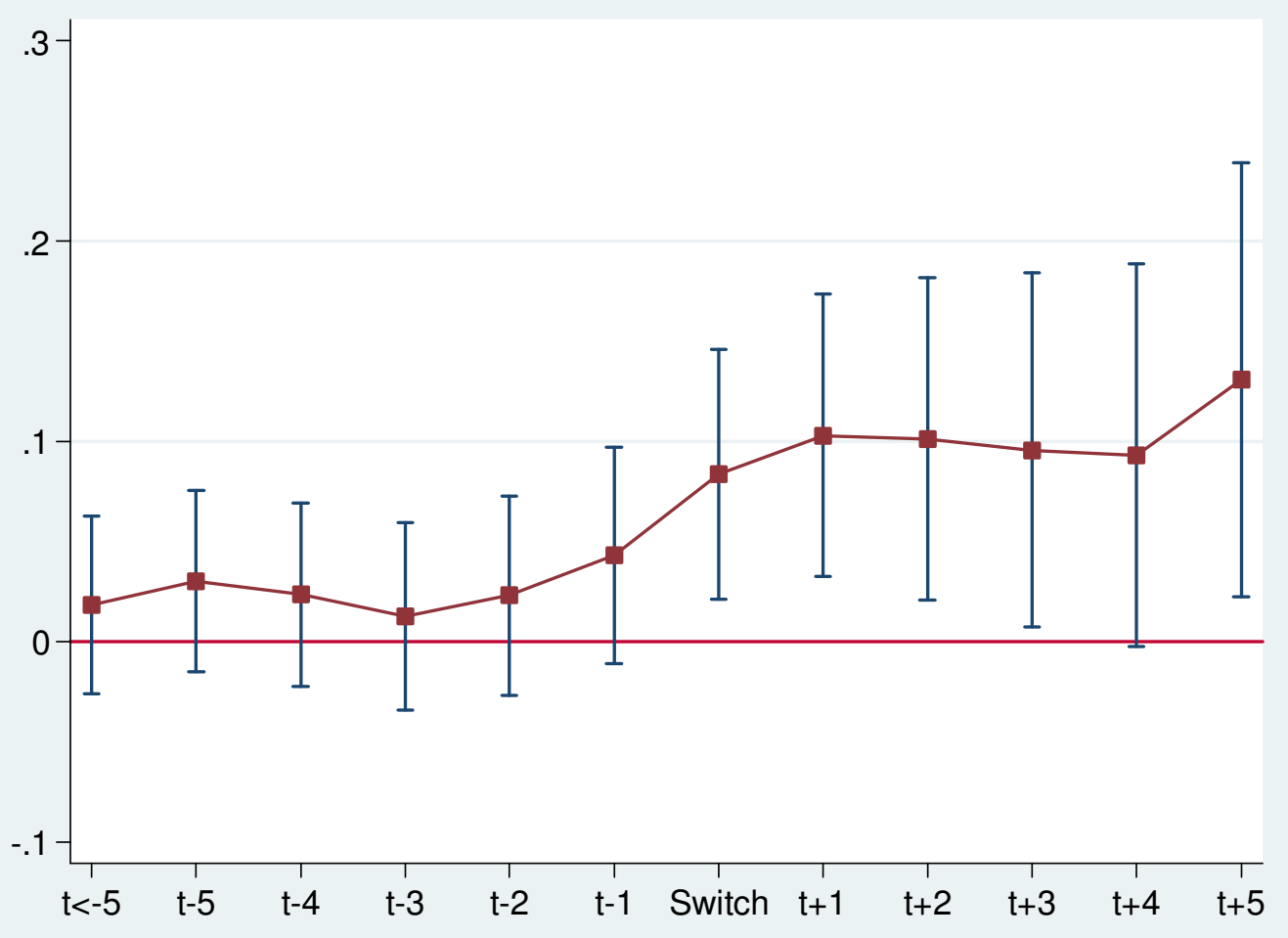

